\title{
Impact of Clinical Pharmacist Interventions and Tele-Monitoring on Clinical Outcomes of Type-2 Diabetes Mellitus Patients
}

\author{
Swetha Reddy Ramidi', Manasa Vancha', Vamshi Guggila1, Syeda Nishat Fathima², Satyanarayana \\ Reddy $\mathrm{K}^{3}$, Rama Manda ${ }^{2}$, Vasudeva Murthy Sindgi2,*
}

1Department of Pharmacy Practice, Jayamukhi College of Pharmacy, Narsampet, Warangal (Rural), Telangana, INDIA. 2Department of Pharmacology, Jayamukhi College of Pharmacy, Narsampet, Warangal (Rural), Telangana, INDIA. ${ }^{3}$ Dr. Satyam's Clinic, Warangal (Urban), Telangana, INDIA.

\begin{abstract}
Background: Since the occurrence of diabetes is increasing, contact between doctor and patient, decreasing, hence as the effective counselling which projects a need for the clinical pharmacist. Aim: To evaluate the outcome among Type 2 diabetes mellitus (T2DM) patients after interventions and tele-monitoring by clinical pharmacist. Patients and Methods: This is a prospective study conducted with a sample size of 140 T2DM patients. The intervention program included patient education and counselling. Patients after assessment of blood glucose parameters, giving information on diabetes and medication adherence and patients received counselling from clinical pharmacist are included in the study. Follow-up was done periodically through phone calls for assessment of health. Blood glucose parameters such as postprandial blood glucose levels (PLBS), Fasting Blood Glucose (FBG), Glycosylated Haemoglobin $\left(\mathrm{HbA}_{1 \mathrm{c}}\right)$ and familiarity about knowledge on diabetes, medication adherence were reassessed after 3-month intervention. Results: There was a significant improvement in FBG, $\mathrm{HbA}_{1 \mathrm{c}^{\prime}}$ PLBS, diabetes knowledge, medication adherence among patients after intervention by the clinical pharmacist Conclusion: Standard counselling and regular follow-up by the clinical pharmacists will improve the glycaemic control among diabetes patients and the role played by clinical pharmacists in educating patients about diabetes management is noticeable.
\end{abstract}

Key words: Glycosylated haemoglobin, Morisky Green Levine Scale, Tele-monitoring, Post prandial blood sugar, Type 2 diabetes mellitus.

\section{INTRODUCTION}

Diabetes mellitus is given prime concern globally due to the increase in morbidity and premature mortalities. ${ }^{1}$ AS IDF Atlas 2017 estimates the incidence of diabetes for the years 2017 and 2045, it has been observed that 425 million people worldwide of age between 20-79 years suffer from diabetes and the figure is anticipated to grow 451 million if the age group of the people is between 18-99 years. It has also been estimated that 693 million people of age 18 to 99 years or 629 million people between 20 to 79 years will suffer from diabetes by $2045 .^{2}$

The WHO defined diabetes mellitus as a lifelong disease caused by deficiency in insulin production, which is inherited or acquired or by the inefficiency of the produced insulin and this deficiency contributes to increased blood glucose concentrations, which damage many systems in the body, especially the blood vessels and nerves. ${ }^{3}$ By comparison, T2DM is more common in humans due to the altered lifestyle that is part of urbanization in developing nations. Many clinical studies have confirmed that type 2 diabetes can be delayed or prevented in high-risk populations and good glycaemic control and other interventions can slow down its complications.

Diabetes management is a joint effort of patients, pharmacists and other health care professionals. The involvement of the
DOI: 10.5530/ijopp.13.1.8

Address for correspondence: Dr.Vasudeva Murthy Sindgi, Department of Pharmacology, Jayamukhi College of Pharmacy, Affiliated to Kakatiya University Narsampet, Warangal (Rural), 506 332, Telangana, INDIA.

Phone no: +91-8143635527

Email Id: sgvmurthy@gmail.com

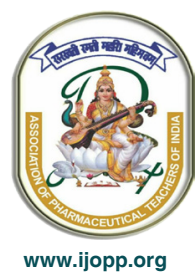


clinical pharmacist leads to better health management in patients. Pharmacists are progressively selected as part of the health maintenance system. ${ }^{4}$ The diabetes management by a pharmacist has shown to increase the outcomes of patients in various medical settings worldwide. ${ }^{5}$ The involvement of the clinical pharmacist improves drug compliance and other factors related to the treatment of diabetes. ${ }^{6}$ The present work is meant to evaluate the effects of interventions and tele-monitoring provided by the clinical pharmacists on the outcomes of type 2 diabetes mellitus patients.

\section{Aim}

To asses the outcome of the patients education and counselling by the pharmacists periodically and reassessing again the familiarity about awareness on diabetes and medication adherence.

\section{Objectives}

To determine the outcome among Type 2 diabetes mellitus (T2DM) patients after interventions and telemonitoring by clinical pharmacist.

\section{METHODOLOGY}

\section{Study procedure}

This was a prospective study done with a sample size of 140 patients in a secondary diabetes care clinic in Warangal over a period of five months from April to August after the approval of the Institutional Review Board (IRB/ JCP/PharmD/2018/1003). The baseline characteristics of patients were recorded using the data collection form. The blood glucose parameters of the subjects are recorded from their medical records at the outset and also after intervention. Patient's knowledge of diabetes and their medication adherence was assessed using modified diabetes knowledge assessment questionnaire and Morisky Green Levine Scale respectively before and after intervention. After assessing patients' diabetes knowledge they were educated on basic aspects of T2DM, diabetes related complications, regarding oral antidiabetics and insulin, signs and symptoms of hypoglycemia and sick day management, proper self- monitoring of blood glucose and healthy lifestyle.

In this study periodic follow up of patients was performed through phone calls. Tele monitoring was done on $30^{\text {th }}$ and $50^{\text {th }}$ day after initial counselling at the clinic. During each session, the clinical pharmacist discussed with each patient about their medication adherence, self-monitoring of glycemic control, diet and exercise and reminded them of their next visit as scheduled. Patients were allowed to open up their enquiries regarding diet, medication, physical activity. To improve medication adherence among patients reminder messages was sent to them.

\section{Study population}

\section{Inclusion criteria}

- Type II diabetes patients of both genders

- Type II diabetes patients with or without hypertension

- $\quad$ Age $\geq 25$ years

- Type II diabetes patients who are willing to visit the hospital on a regular basis.

\section{Exclusion criteria}

- Type 1 diabetes mellitus patients

- Patients with pre-existing endocrine diseases

- Type II diabetes patients with comorbidities

- Type II diabetes patients who are unable to communicate verbally

- Patients with psychiatric illness

\section{Study materials}

1. Modified diabetes knowledge assessment questionnaire: Adapted for South Asian countries to assess the patient knowledge and understanding of diabetes and its management for the study.

2. Counselling aids: patient information leaflets, prescription aids and other support materials used to educate the patients.

3. Data collection form: This form is used to collect information regarding patient's socio demographic details, lab investigations, meal plan, exercise, treatment plan etc.

4. Morisky Green Levine scale: Used to assess medication adherence in the patients.

\section{Clinical pharmacist interventions}

This includes providing individualised patient counselling using visual aids on various aspects related to diabetes mellitus such as regarding diabetes and its complications, signs, symptoms of hyperglycaemia, hypoglycaemia and its management, diabetic ketoacidosis, about oral hypoglycaemic agents and their possible side effects and insulin administration techniques, information on 
importance of $\mathrm{HbA}_{1 \mathrm{c}}$ test and target range of all blood glucose parameters was provided, individualised diet plans were suggested to the patients, importance of physical activity, regular blood glucose monitoring and annual dental, ophthalmic examination was explained. Pamphlets with foot care and summer tips for diabetes patients were given.

\section{Statistical analysis}

Data analyzed using SPSS version 25.0 (SPSS Inc., Chicago, USA) descriptive statistics were calculated (the mean and Standard Deviation (SD) and 95\% Confidence Interval (CI) for quantitative variables and percentages for qualitative variables). For the assessing between pre intervention and post intervention outcomes used paired $t$-test and A level of significance of $5 \%(p<0.05)$ was used in a conventional way to reject the null hypothesis. Multiple regression analysis was done to find out the factors affects $\mathrm{HbA}_{1 c^{\circ}}$

\section{RESULTS}

Initially a total of 160 patients were evaluated by applying inclusion and exclusion criteria finally 140 members were recruited. Among them, 125 members successfully completed this study, remaining 15 were withdrawn during the study without our consent due to multiple reasons like financial issues, individual interest, busy lifestyle and due to lack of knowledge. The demographic details of the subjects were presented in Table 1 .

\section{Assessment of outcome in study population}

As shown in Table 2, all blood glucose parameters $\left(\mathrm{HbA}_{1 \mathrm{c}}\right.$, FBS, PLBS) reduced significantly after intervention $(p<0.0001)$. It was observed that the mean $\mathrm{HbA}_{1 \mathrm{c}}$ was decreased to $7.3 \%$ after 3 months of intervention. The number of patients with target FBS (below $115 \mathrm{mg} / \mathrm{dL}$ ) and PLBS (below $160 \mathrm{mg} / \mathrm{dL}$ ) were raised after clinical pharmacist interventions.

\section{Medication adherence}

Medication adherence was evaluated at the beginning of the study. Multiple reasons were noted for non-adherence to the provided treatment regimen such as busy schedule of the individuals, forgetfulness and financial problems. It was noted that medication adherence significantly improved after 3 months of intervention. The percentage of patients with poor adherence decreased from baseline $9.6 \%$ to $7.2 \%$ by the end of the study. While the subjects with high adherence increased from 5.6\% to 36\% after intervention by the clinical pharmacists.
Table 1: Demographic details of the participants.

\begin{tabular}{|c|c|}
\hline Variables & $n(\%)$ \\
\hline \multicolumn{2}{|l|}{ Age } \\
\hline Below 30 & $6(4.28)$ \\
\hline Above 30 & $134(95.71)$ \\
\hline \multicolumn{2}{|l|}{ Gender } \\
\hline Males & $79(56.42)$ \\
\hline Females & $61(43.57)$ \\
\hline \multicolumn{2}{|l|}{ Locality } \\
\hline Rural & $61(43.57)$ \\
\hline Urban & $79(56.42)$ \\
\hline \multicolumn{2}{|l|}{ Annual Income } \\
\hline$>1$ lakh & $80(57.14)$ \\
\hline$<1$ lakh & $60(42.85)$ \\
\hline \multicolumn{2}{|l|}{ Level of Education } \\
\hline Illiterate & $56(40)$ \\
\hline Educated & $84(60)$ \\
\hline \multicolumn{2}{|l|}{ Occupation } \\
\hline Employed & $95(67.86)$ \\
\hline Unemployed & $45(32.14)$ \\
\hline \multicolumn{2}{|l|}{ Duration of Diabetes } \\
\hline$<1$ year & $15(10.71)$ \\
\hline $1-5$ years & $47(33.57)$ \\
\hline $6-10$ years & $44(31.42)$ \\
\hline $11-20$ years & $31(22.14)$ \\
\hline $21-30$ years & $3(2.14)$ \\
\hline Hypertension & $73(52.1)$ \\
\hline Alcohol consumption & $40(28.57)$ \\
\hline Smoking & $7(5)$ \\
\hline Tobacco chewing & $3(2.14)$ \\
\hline
\end{tabular}

\section{Response to dosing card}

The primary step for improving patient medication adherence involves accurately assessing whether or not patients have followed the treatment recommended to them. In this study, patients were provided with a customized check card where patients updated their regular medicine intake and positive result observed in most of the patients (20.8\%), which further led to better clinical outcomes. Few patients returned incompletely filled in form $(16.8 \%)$. All the patients in spite of returning incompletely filled in form had acceptable adherence to medication regimen.

\section{Response to diabetes knowledge assessment questionnaire}

Awareness regarding the disease plays a significant role in preventing, managing and controlling any chronic illness. In this study, patient knowledge of diabetes mellitus 
Table 2: Comparison of blood glucose parameters before and after intervention.

\begin{tabular}{|c|c|c|c|c|c|c|c|}
\hline \multirow[b]{2}{*}{ Variables } & \multicolumn{2}{|c|}{ Pre intervention } & \multirow{2}{*}{$\begin{array}{c}\text { Confidence Interval } \\
\mathbf{n}\end{array}$} & \multicolumn{2}{|c|}{ Post intervention } & \multirow{2}{*}{$\begin{array}{l}\text { Confidence } \\
\text { Interval }\end{array}$} & \multirow[t]{2}{*}{$P$ value } \\
\hline & $\mathbf{n}$ & Mean \pm SD & & $\begin{array}{l}\text { Mean } \\
\pm S D\end{array}$ & & & \\
\hline \multicolumn{8}{|l|}{$\mathrm{HbA}_{1 \mathrm{c}}(\%)$} \\
\hline Good Control & 20 & $6.66 \pm 0.30$ & $6.52-6.80$ & 40 & $6.40 \pm 0.39$ & $6.28-6.49$ & $<0.0001$ \\
\hline Fair control (7.1-8) & 45 & $7.50 \pm 0.28$ & $7.42-7.59$ & 45 & $7.40 \pm 0.27$ & $7.31-7.45$ & $<0.0001$ \\
\hline $\begin{array}{c}\text { Unsatisfactory Control } \\
(8.1-10)\end{array}$ & 34 & $8.69 \pm 0.55$ & $8.51-8.90$ & 29 & $8.82 \pm 0.54$ & $8.56-9.017$ & $<0.0001$ \\
\hline Poor control $(>10)$ & 21 & $11.48 \pm 1.80$ & $10.5-12.08$ & 6 & $11.31 \pm 1.07$ & $9.62-12.05$ & $<0.0463$ \\
\hline \multicolumn{8}{|l|}{ FBS } \\
\hline Below- 115 & 30 & $102.26 \pm 11.53$ & $98.06-106.4$ & 56 & $98.78 \pm 10.79$ & $95.91-101.3$ & $<0.0001$ \\
\hline Above-115 & 95 & $165 \pm 51.09$ & $153.8-174.6$ & 69 & $142 \pm 23.33$ & $136.1-148.0$ & $<0.0001$ \\
\hline \multicolumn{8}{|l|}{ PLBS } \\
\hline Below-160 & 18 & $145.55 \pm 7.36$ & $141.9-149.2$ & 58 & $140.93 \pm 15.97$ & $135.4-143.8$ & $<0.0001$ \\
\hline Above-160 & 107 & $254.04 \pm 68.9$ & 239.6-265.5 & 67 & $197.97 \pm 33.4$ & 189.1-204.5 & $<0.0001$ \\
\hline
\end{tabular}

was assessed using Modified Diabetes Knowledge Questionnaire (MDKQ) during pre and post intervention (Table 3). The study ascertained the majority of the patients unaware of sick day management, importance of $\mathrm{HbA}_{1 \mathrm{c}}$ and its target range, the necessity of selfmonitoring of blood glucose. After intervention, it was interesting to note that the majority of respondents had good knowledge regarding diabetes irrespective of their educational status, all the values are statistically significant.

\section{Out comes on tele-monitoring}

To get better clinical outcomes during treatment period, patients were counselled using their contact number. Tele-monitoring executed on $30^{\text {th }}$ and $50^{\text {th }}$ day after initial counselling. Positive response was obtained from most of the participants and follow up was done on their respective dietary plan and for their physical activities. This study noticed that patients who had a sedentary lifestyle earlier started engaging in physical activities and very few quit smoking and alcohol consumption. All the reciprocated individuals ensued prescribed diet plan throughout the study. Comprehensively there were only few enquiries from the patients with reference to the drugs $(4.28 \%)$, disease $(7 \%)$, diet $(7.1 \%)$ and physical activity $(5.7 \%)$. Information was provided to most of the patients on their disease and diet, physical activity related complaints while few are suggested to visit the hospital only to the patients requiring a change in dose frequency, hypoglycaemic episode, experienced ADR. Reminder messages and contacted over phone to the patients from time to time to improve their medication adherence.

\section{Factors effecting $\mathrm{HbA}_{10}$}

Strict glycemic control is necessary in diabetes patients to prevent the development of complications. This can be accomplished by determining factors that affect glycemic control. In this study multiple regression analysis was used examine the variables which may affect post $\mathrm{HbA}_{1 \mathrm{c}}$. It was observed that scores of adherence after 3 months of intervention was a major influencing factor and found to be statistically significant. Every single degree gain in score of medication adherence after intervention by clinical pharmacist resulted in a base reduction of $\mathrm{HbA}_{1 \mathrm{c}}$ by $1 \%$. However, it was found that the other factors such as age, gender, educational status, duration of diabetes have not significantly influenced $\mathrm{HbA}_{1 \mathrm{c}}$ (Table 4) and the various other risk factors observed in patient population shown in Figure 1.

\section{DISCUSSION}

High blood sugar levels are the main risk factor to develop diabetic complications. Since it's not feasible for a patient to be under doctor supervision all the day and diabetes is a lifelong progressive disorder and it requires a good knowledge of patient about various aspects of effective blood glucose control.

The emphasis of this work is to infer the dignity of a clinical pharmacist involvement in diabetes management. Some of the interventions used during this study to analyze the effect of those interventions on patient outcomes with respect to diabetes. Patient's diabetic knowledge assessment, medication adherence and blood glucose parameters ( $\mathrm{HbA}_{1 \mathrm{c}}, \mathrm{FBS}$ and PLBS) were 
Table 3: Patient response to modified DKQ before and after intervention.

\begin{tabular}{|c|c|c|c|c|}
\hline \multirow[t]{2}{*}{ S.nos } & \multirow[t]{2}{*}{ Contents of modified DKQ } & \multirow{2}{*}{$\begin{array}{c}\text { Pre } \\
\text { Intervention }\end{array}$} & \multirow{2}{*}{$\begin{array}{c}\text { Post intervention } \\
\text { Mean } \pm \text { SD }\end{array}$} & \multirow[t]{2}{*}{$P$-value } \\
\hline & & & & \\
\hline 1 & Diabetes is a condition & $0.95 \pm 0.21$ & $1 \pm 0$ & 0.0247 \\
\hline 2 & Which of the following statements about diabetic diet are true & $0.18 \pm 0.38$ & $1 \pm 0$ & $<0.0001$ \\
\hline 3 & $\begin{array}{c}\text { Why is doing regular exercise or being physically active good for } \\
\text { health }\end{array}$ & $0.21 \pm 0.20$ & $0.89 \pm 0.13$ & $<0.0001$ \\
\hline 4 & $\begin{array}{l}\text { Do you know how often should people with diabetes exercise or be } \\
\text { physically active }\end{array}$ & $0.53 \pm 0.50$ & $1 \pm 0$ & $<0.0001$ \\
\hline 5 & $\begin{array}{l}\text { What are the habits which help a person with diabetes to prevent } \\
\qquad \text { complications }\end{array}$ & $0.27 \pm 0.27$ & $0.88 \pm 0.14$ & $<0.0001$ \\
\hline 6 & $\begin{array}{l}\text { What is the ideal fasting blood glucose levels a person with diabetes } \\
\text { should aim for }\end{array}$ & $0.52 \pm 0.50$ & $1 \pm 0$ & $<0.0001$ \\
\hline 7 & Why are people with diabetes advised to test their own blood glucose & $0.03 \pm 0.009$ & $0.80 \pm 0.24$ & $<0.0001$ \\
\hline 8 & What is $\mathrm{HbA}_{1 \mathrm{c}}$ & $0.08 \pm 0.15$ & $0.76 \pm 0.21$ & $<0.0001$ \\
\hline 9 & What is $\mathrm{HbA}_{1 \mathrm{c}}$ which a person with diabetes should aim for & $0.08 \pm 0.27$ & $1 \pm 0$ & $<0.0001$ \\
\hline 10 & What should a person with diabetes do if she/he become ill & $0.16 \pm 0.07$ & $0.83 \pm 0.22$ & $<0.0001$ \\
\hline 11 & Well managed diabetes decreases the risk of & $0.36 \pm 0.31$ & $0.94 \pm 0.10$ & $<0.0001$ \\
\hline 12 & $\begin{array}{l}\text { Person with diabetes need a medical check-up for their eyes, nerves } \\
\text { and kidney function atleast once a year }\end{array}$ & $0.93 \pm 0.24$ & $1 \pm 0$ & 0.0247 \\
\hline 13 & What are the foot problems that can devlop in a person with diabetes & $0.09 \pm 0.14$ & $0.78 \pm 0.17$ & $<0.0001$ \\
\hline 14 & Which of the following statements about diabetes medication are true & $0.19 \pm 0.39$ & $0.98 \pm 0.12$ & $<0.0001$ \\
\hline 15 & $\begin{array}{l}\text { If a person with diabetes has a hypoglycemia reaction, what should } \\
\text { be done }\end{array}$ & $0.94 \pm 0.15$ & $0.98 \pm 0.07$ & 0.0195 \\
\hline 16 & $\begin{array}{c}\text { A person with type } 1 \text { diabetes feeling unwell and unable to eat, what } \\
\text { should be done }\end{array}$ & $0.01 \pm 0.10$ & $0.55 \pm 0.23$ & $<0.0001$ \\
\hline 17 & $\begin{array}{l}\text { What are the precautions a person with diabetes should take before } \\
\text { travelling }\end{array}$ & $0.16 \pm 0.12$ & $0.76 \pm 0.18$ & $<0.0001$ \\
\hline 18 & $\begin{array}{l}\text { What a person with diabetes should do if he/she experiences side } \\
\text { effects }\end{array}$ & $0.11 \pm 0.14$ & $0.77 \pm 0.24$ & $<0.0001$ \\
\hline
\end{tabular}

Table 4: Multiple regression analysis on factors effecting $\mathrm{HbA}_{10}$

\begin{tabular}{ccc}
\hline Variables & Coefficient & $\boldsymbol{P}$ value \\
\hline Age & -0.002044 & 0.7056 \\
Education & 0.09467 & 0.4018 \\
Gender & 0.1211 & 0.3887 \\
Duration of diabetes & 0.002281 & 0.8044 \\
Occupation & -0.109 & 0.1836 \\
$\begin{array}{c}\text { Scores of adherence after } \\
\text { the intervention }\end{array}$ & -0.2136 & 0.0334 \\
$\begin{array}{c}\text { Scores of adherence } \\
\text { before intervention }\end{array}$ & -0.01261 & 0.9505 \\
\hline
\end{tabular}

documented at the beginning before clinical pharmacist intervention. Later on a period of 90 days (3 months), patient's diabetic knowledge, medication adherence and blood glucose parameters were reassessed to fulfil the aim of the study. It was found that the levels of $\mathrm{HbA}_{1 \mathrm{c}}$, FBS, PLBS, diabetes knowledge and medication adherence

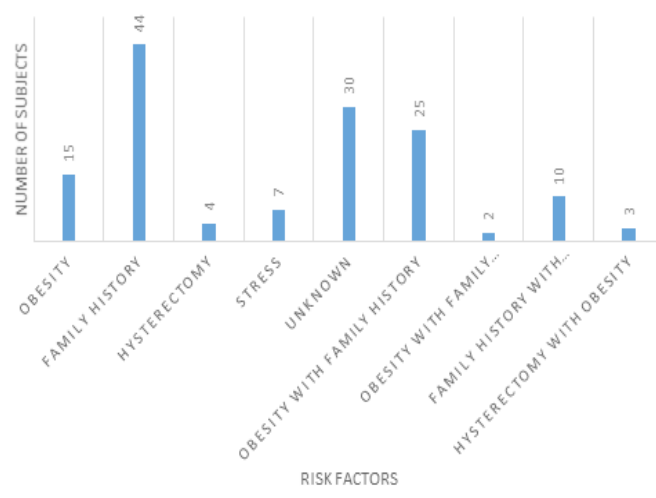

Figure 1: Risk factors observed in study population.

significantly improved in the subjects after intervention by clinical pharmacist and identical results were observed in preceding research work. ${ }^{7,8}$

Medication adherence can be improved amongst diabetes patients by the participation of clinical Indian Journal of Pharmacy Practice, Vol 13, Issue 1, Jan-Mar, 2020 
pharmacist. ${ }^{9}$ Similarly in our study there was a significant improvement in patient's medication adherence due to clinical pharmacist interventions i.e. by educating patients on the importance of proper medication adherence, understanding their reasons for non-adherence and providing a customized dosing check card which acts as a reminder. This dosing card also developed consciousness among patients towards medication adherence, which assisted the health care provider to understand patient's medical adherence. Patient's knowledge of diabetes has been usually poor among developed and developing countries. ${ }^{10-12}$ In this study it was observed that major portion of the participants had an average knowledge of diabetes.

It was apparent that there was no association between the diabetes knowledge of the patient and their glycemic control. ${ }^{13}$ In this present study, it was discovered that there is no relationship between $\mathrm{HbA}_{1 \mathrm{c}}$ levels and their diabetes knowledge. Present study revealed majority of patients who were uneducated had a significantly lower DKQ score. Overall observations states that the majority of patients were not able to respond to a few questions which include quires regarding the importance of $\mathrm{HbA}_{1 \mathrm{c}}$ the necessity of self-monitoring of blood sugar, sick day management, all this is due to lack of awareness among patients about diabetes. However, after clinical pharmacist intervention, there is a significant improvement recorded in patient's knowledge about diabetes by the end of the study. As mentioned earlier, tele-monitoring is the unique feature in this study. A study found that pharmacistprovided interventions facilitated by tele-monitoring resulted in significant improvements in diabetes control among patients. ${ }^{14}$ Similar observations recorded in the present study where follow-up post counselling performed through telephone calls. Patients were very responsive, the majority of patients found it useful and voluntarily sought advice, asked few queries about drug usage, safeguarding and to store the drugs in the time of travelling, potential side effects with anti-diabetic drugs, missing dose, hypoglycaemic episode and infections. Enquiries regarding to diet includes what is the ideal diabetes diet. Indirectly tele-monitoring is a significant contributor to effective blood glucose management.

\section{CONCLUSION}

Though overall knowledge about diabetes among the patients was acceptable, through this study it was noted that there are few areas where improvement in knowledge is however required among patients. This study provided evidence on the importance of clinical pharmacists in diabetes management team. There was a noteworthy improvement in glycemic control and mental health functioning by clinical pharmacist led tele-monitoring program. Tele-monitoring was well accepted by patients. Tele- monitoring would be an excellent approach by clinical pharmacist in providing better health care management for many other disease conditions. We conclude that the results of this study are positive and indicate a dire need of clinical pharmacist participation in diabetes management.

\section{ACKNOWLEDGEMENT}

Authors are grateful to Dr. K Satyanarayana Reddy for utilising the services of the Dr. Satyam Clinic, Hanamakonda, Warangal (Urban).

\section{CONFLICT OF INTEREST}

The authors declare no conflict of interest.

\section{ABBREVIATIONS}

T2DM: Type 2 diabetes mellitus; PLBS: Post prandial blood sugar; FBG: Fasting blood glucose; $\mathbf{H b A}_{1 \mathrm{c}}$ : Glycosylated haemoglobin; IDF: Indian Diabetes Federation; WHO: World Health Organisation; ADR: Adverse drug reactions; DKQ: Diabetes knowledge assessment questionnaire.

\section{SUMMARY}

This prospective study is all about effective education of diabetes patients by the clinical pharmacists by the way of tele- monitoring and using counselling aids. The interventions and follow up and counselling of the patients resulted in improved levels of PLBS, FBG and $\mathrm{HbA}_{1 \mathrm{c}}$ with betterment of medication adherence observed.

\section{REFERENCES}

1. Roglic G, Unwin N, Bennett PH, Mathers C, Tuomilehto J, Nag S, et al. The burden of mortality attributable to diabetes: realistic estimates for the year 2000 . Diabetes Care. 2005;28(9):2130-5.

2. International diabetes federation: $8^{\text {th }}$ edition. IDF Atlas. 2017.

3. WHO. Definition, Diagnosis and Classification of Diabetes Mellitus and its Complications. Report of WHO Consultation. Part 1: Diagnosis and Classification of Diabetes Mellitus. Geneva: WHO Department of Non-communicable Disease Surveillance. 1999;1-59.

4. Ghani K, Wasif G, Maria G. Pharmacy Teaching and practice problems in developing countries: Review. Int J Pharm Teach Pract. 2010;1(1):11-17.

5. Collins C, Limone BL, Scholle JM, Coleman Cl. Effect of pharmacist intervention on glycemic control in diabetes. Diabetes Res Clin Pract. 2011;92(2):145-52.

6. Alhabib S, Aldraimly A, Aifarhan A. An evolving role of clinical pharmacists in managing diabetes: Evidence from the literature. Saudi Pharmaceutical Journal. 2016;24(4):441-6.

7. Rothman R, Malone R, Bryant B, Horlen C, Pignone M. Pharmacist-led, primary care-based disease management improves haemoglobin A1cin high-risk patients with diabetes. Am J Med Qual. 2003;18(2):51-8.

8. Mehuys E, Bortel V, Bolle LLD, Tongelen IV, Annemans L, Remon JP. Effectiveness of a community pharmacist intervention in diabetes care: A randomized controlled trial. J Clin Pharm Ther. 2011;36(5):602-13. 
9. Lindenmeyer A, Hearnshaw H, Vermeire A, Royen PV, Wens J, Biot Y. Interventions to improve adherence to medication in people with type 2 diabetes mellitus: A review of the literature on the role of pharmacists. J Clin Pharm Ther. 2006;31(5):409-19.

10. Wee HL, Ho HK, Li SC. Public awareness of diabetes mellitus in Singapore. Singapore Med J. 2002;43(3):128-34.

11. Al-Maskari F, El-Sadig M, Al-Kaabi JM, Afandi B, Nagelkerke N, Yeatts KB. Knowledge, attitude and practices of diabetic patients in the United Arab Emirates. Journal Pone. 2013;8(1):e52857.
12. Deepa M, Bhansali A, Anjana RM, Pradeepa R, Joshi SR, Joshi PP, et al. Knowledge and awareness of diabetes in urban and rural India: The Indian council of medical research India Diabetes study (phase 1): Indian council of medical Research India diabetes 4. Indian J Endocrinol Metab. 2014;18(3):37985.

13. Beeney LJ, Dunn SM. Knowledge improvement and metabolic control in diabetes education: Approaching the limits?. Patient Educ Couns. 1990;16(3):217-29.

14. McWhorter-Shane L, McAdam-Marx C, Lesile L, Marta P, Sarah W, Jeffery M, et al. Augmenting Tele monitoring Interventions by Targeting patient Needs in a primary Hispanic Underserved population. Diabetesspectr. 2016;29(2):121-7. 